\title{
Sudanese infant with Fraser syndrome
}

\section{Aamir Yassin ${ }^{1 *}$, Somaya Al-asad ${ }^{2}$, Sausan Abdulmonim ${ }^{3}$, Amani Hashim ${ }^{3}$,}

Awadallah Hassan ${ }^{2}$.

\begin{abstract}
: signs.

raser syndrome (FS) is a rare autosomal recessive disorder (Figure1).

Cryptophthalmos (CO), or "hidden eye" is a term invented by Zehender and Manz in $1872^{1}$. Since their original description till 1995, approximately 149 cases of complete or partial cryptophthalmos have appeared in the world English literature ${ }^{2}$. Fraser $^{3}$ defined the first report of autosomal recessive cryptophthalmos syndrome, while Francois ${ }^{4}$ observed the other main features of hand, orofacial and genital abnormalities. There are more than 200 published case reports of patients with $\mathrm{CO}$ and FS and several comprehensive reviews have previously been published ${ }^{2}$.
\end{abstract}

We are reporting here a case of Fraser syndrome which is a very rare autosomal recessive disorder characterized by cryptophthalmos, cutaneous syndactyly, craniofacial dysmorphism, malformation of the upper airways and genitourinary tract. Diagnosis of Fraser syndrome is based on clinical

Key wards: Fraser symdrome (FS), cryptophthalmos (CO), syndactyly

\section{Case report:}

This was a 35 days female, a second baby of consanguineous healthy parents; father 24 years and mother 25 years.

She was an outcome of a normal vaginal delivery following full term uncomplicated pregnancy. Mother was not on regular antenatal care. She cried immediately after birth, started feeding and passed urine and meconium during the first 24 hours. The midwife noticed the complete fusion of the baby eyelids and abnormally fused fingers (figure 2). She advised the parents to seek medical advice. There was family history of similar conditions; two of her paternal cousins

1. Registrar of pediatrics, OIU, Khartoum Sudan.

2. Departm of pediatrics, Omdurman Islamic University.

3. Department of Pediatrics, Emergency

Hospital.Sudan.

* Correspondence: amir-yasin@hotmail had similar clinical abnormalities and died immediately or after few days of birth due to severe respiratory distress

She was seen initially in ophthalmology clinic and then was referred to Omdurman Pediatrics Emergency Hospital.

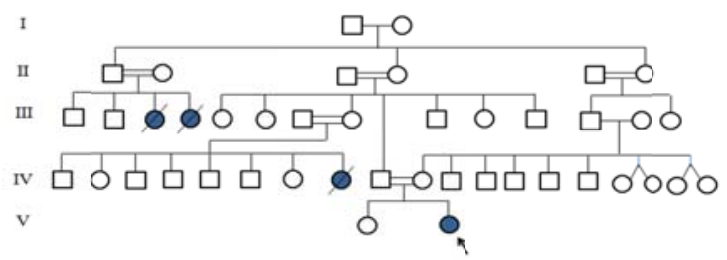

Figure (1) the family pedigree

There was no history of cough, cyanosis or difficulty during feeding. There were no change in bowel habits, no vomiting or abdominal distension. The urine was normal in amount, color and frequency. There patient can move her limbs normally, no weakness or abnormal movements,

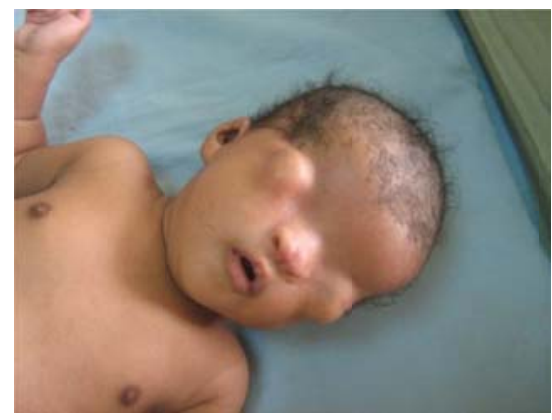

Figure 2: bilateral cyptophthalmos

On examination her weight was $4.3 \mathrm{~kg}$, crown heel length was $55 \mathrm{~cm}$ and head circumference was $37 \mathrm{~cm}$. The craniofacial 
examination showed prominent forehead, opened anterior fontanelle $7 \mathrm{x} 4 \mathrm{~cm}$, depressed nasal bridge, broad nose with midline nasal groove, bilateral $\mathrm{CO}$ with presence of both eyeballs and absence of eye brows and lashes (figure2). Both ears were small and low sited (figure 3). She had cutaneous syndactyly in both hands and feet and bilateral brachydactyly of the big toe (figure4: a \& b). Genitalia showed clitoromegaly with hypoplasia of the labia and she had low set umbilicus (figure 5). Ultrasound for abdomen showed bilateral dysplastic kidneys with normal internal female genital organs. Echo cardiography showed normal heart structure and function.

These clinical findings were consistent with the diagnosis of Fraser's syndrome.

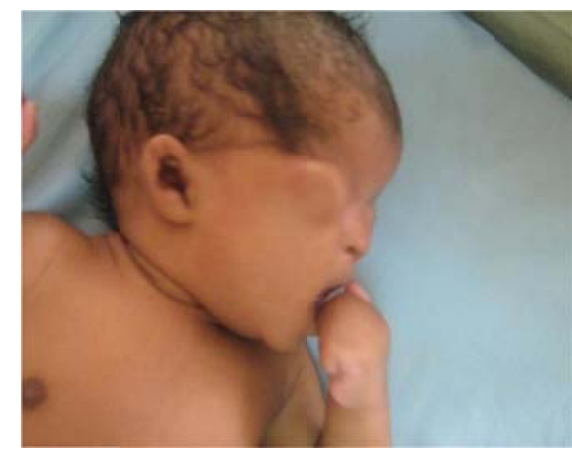

Figure 3: low set ear, depressed nasal bridge (a)

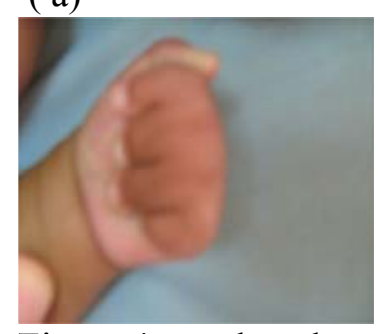

Figure 4: syndactyly (b)

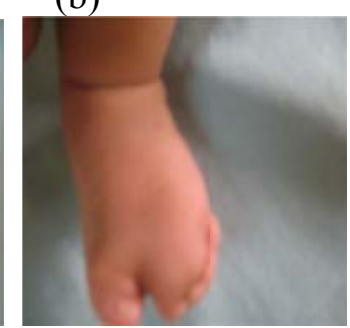

\section{Discussion:}

The diagnostic criteria for Fraser syndrome are classified to major and minor criteria. The major criteria are: cryptophthalmos, syndactyly, abnormal genitalia and sibling with FS; while the minor criteria are: congenital malformation of nose, ears, larynx, cleft lip and/or palate, skeletal defects, umbilical hernia ,renal agenesis and mental retardation. The criteria to distinguish isolated $\mathrm{CO}$ from $\mathrm{CO}$ with other malformations and FS were provided by Thomas et al 1986following a study of 124 cases of $\mathrm{CO}^{5}$.

Two major criteria and one minor criterion or one major and at least four minor criteria were required for the diagnosis of $\mathrm{FS}^{5}$. Our patient had two major criteria (cryptophthalmos and syndactyly) and two minor features (clitromegaly and renal agenesis). From the 117 cases reported ${ }^{2}$; females were $48.7 \%$; consanguinity was present in $24.8 \%$ of cases; and the most common consanguineous union was first cousins; $41 \%$ of cases had a significant family history of a relative with $\mathrm{CO}$ or physical findings suggestive of FS. Consanguinity marriage and family history were evident in our case. The average paternal age was 27 years of age and the average maternal age was 24 years of age which is similar to ages of our patient's parents.

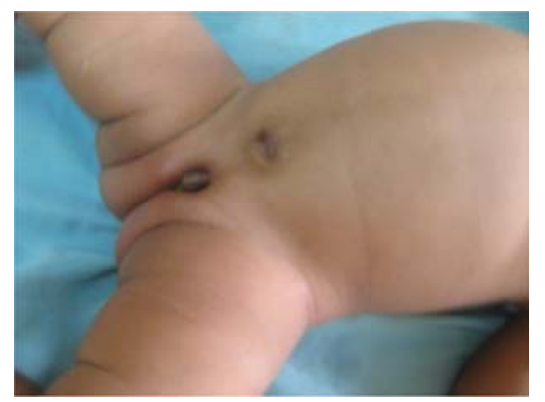

Figure 5: clitromegaly, low set umblicus

Slavotinek and Tifft ${ }^{2}$ also considered additional phenotypes associated with FS including other occular abnormalities (absent eyebrows or eyelashes, coloboma of the eyelid, microphthalmia, anophthalmia and corneal opacification), hand abnormalities (brachydactyly, nail hypoplasia and abnormal palm creases). Clitoromegaly in females and cryptorchidism in males were the commonest. Our patient had clitoromegaly and abnormal hands.

Cardiac malformations include hypertrophy of the left ventricle, coarctation of the aorta, atrial septal defect, truncus arteriosus and ventricular septal defect. Dextrocardia and 
Aamir Yassin et al.

transposition of the great vessels were also noted, none of these were seen in this case.

\section{References :}

1. Konrad H, Merriam JC, Jones IS. Rehabilitation of a child with partial unilateral cryptophthalmos and multiple congenital anomalies. Trans Am Ophthalmol Soc 1995;93:219-40.

2. Slavotinek A M, Tifft C J. Fraser syndrome and cryptophthalmos: review of the diagnostic criteria and evidence for phenotypic modules in complex
Sudanese infant with Fraser syndrome

malformation syndromes J Med Genet 2002;39: 623-633

3. Fraser GR. Our genetic load: A review of some aspects of genetic variation. Ann Hum Genet 1962;25:387-415.

4. François J, De Rouck A, Fernandez-Sasso D. Electroretinography and electro-oculography in diseases of the posterior pole of the eye. Bibl Ophthalmol. 1969;80:132-63.

5. Thomas IT, Frias JL, Felix V et al. Isolated and syndromic cryptophthalmos. Am J Med Genet 1986;25:85-98. 